\title{
In Vitro Culture of 'Myrobalan' (Prunus cerasifera Ehrh.) Embryos
}

\author{
Arancha Arbeloa ${ }^{2}, M^{a}$ Elena Daorden ${ }^{1}$, Elena García, \\ Pilar Andreu, and Juan A. Marín \\ EE Aula-Dei-CSIC, Pomology, Avenida Montañana 1005, Zaragoza, 50059 \\ Spain
}

Additional index words. in vitro germination, seed size, rootstock breeding

Abstract. In vitro embryo culturing has arisen as a powerful tool for embryo germination of low-viability seeds. This tool has been used to germinate seeds of early-maturing or hybrid Prunus species. 'Myrobalan' (Prunus cerasifera Ehrh.) is a widely used rootstock for plum and apricot cultivars and its interspecific hybrids have a clear potential for breeding purposes. However, early seed abortion is often a problem in interspecific crosses because no protocol has been established yet for 'Myrobalan' seeds. In this work, we developed a procedure for in vitro germination of embryos of different sizes. Various factors affecting embryo germination such as the culture media, the presence of cotyledons, the stratification temperature, and the embryo size were tested in three different 'Myrobalan' clones. The developed protocol includes the use of full embryos that were stratified at $4{ }^{\circ} \mathrm{C}$ and cultured in $\mathrm{C} 2 \mathrm{~d}$ culture medium. The germination rate was strongly affected by the embryo size and reached $90 \%$ germination with intermediate- to large-sized embryos $(6.5$ to $10 \mathrm{~mm})$. However, smaller embryos could also be germinated, and up to $30 \%$ germination was achieved with 0.5 - to 2 -mm long embryos. The results obtained here provide a protocol for in vitro germination of 'Myrobalan' embryos that will likely be helpful in breeding programs.

Breeding programs in fruit trees are usually based on the introgression of genes through interspecific distant crosses. These hybridizations produce aborted seeds because their development is arrested at an early stage; therefore, it is difficult for the seeds to germinate with conventional methods. Lowviability seeds also occur either when the embryos come from early-maturing fruits where seeds do not reach the mature stage or when the embryos come from stenospermic seedless fruits such as in grape varieties. In all these cases, embryo rescue has been successfully used to overcome the low viability of these seeds (Ramming, 1990).

In Prunus, since the early Tukey experiments (Tukey, 1933), there have been a number of examples of the use of ovule culture in breeding programs, primarily for earlymaturing peaches and nectarines (Emershad and Ramming, 1994; Pinto et al., 1994; Ramming, 1985; Ramming et al., 2003; Sinclair and Byrne, 2003). In addition, in vitro culturing of embryos has been used to overcome early embryo abortion in interspecific hybrids (Ledbetter et al., 1998; Liu et al., 2007; Stanys, 1998).

Received for publication 11 June 2009. Accepted for publication 31 July 2009 .

This work was partially supported by the INIAFEDER project RF2008-00029-C02-01 and by the Grupo de Excelencia A-43 (Gobierno de Aragón). We thank María Herrero for her critical review of the manuscript.

${ }^{1}$ Permanent address: EEA San Pedro-INTA, $\mathrm{CCN}^{\circ}$ 43, 2930 Buenos Aires, Argentina.

${ }^{2}$ To whom reprint requests should be addressed; e-mailarbeloa@eead.csic.es.
The success of raising plants from immature or aborted embryos depends on their stage of maturity at culture time. Even very immature embryos have been successfully rescued using complex media and procedures by culturing whole ovules or even ovaries (Sharma et al., 1996). Several studies in the Prunus species have related success in in vitro embryo germination to embryo size in peach (Chaparro and Sherman, 1994), apricot (Burgos and Ledbetter, 1993), or interspecific peach hybrids (Liu et al., 2007).

Fruit breeding programs specifically use in vitro embryo culture because fruit tree breeding is a long process and because postzygotic incompatibility barriers with low-viability seeds often appear. 'Myrobalan' (Prunus cerasifera Ehrh.) has been largely used as a fruit tree rootstock for plum and apricot because of its rusticity and adaptability to several soil conditions (Wertheim, 1998). In addition, 'Myrobalan' has also been used as a parent in several rootstock and edible plum breeding programs (Okie and Weinberger, 1996). However, no in vitro protocols have yet been developed for 'Myrobalan' seeds. In this work, we describe a procedure for the in vitro culturing of 'Myrobalan' embryos to facilitate plant recovery from interspecific crosses. For this purpose, we performed different experiments with three 'Myrobalan' genotypes to determine the culture media composition and the stratification temperature. In addition, the effect of the embryo size on germination was shown to be a critical factor for successful rescue of embryos.

\section{Materials and Methods}

Plant material. Three 'Myrobalan' ( $P$. cerasifera) clones (named 'Myrobalan 1' to
'Myrobalan 3') maintained in the orchard collection of the Experimental Research Station of Aula Dei-CSIC (Zaragoza, Spain) were selected based on their appropriate characteristics as fruit tree rootstocks. In the first experiment, immature fruits were collected 12 weeks after pollination from openpollinated trees. Second, to obtain seeds with different embryo sizes, because the openpollinated fruits rarely contained small embryos, seeds were collected from $\mathrm{F}_{1}$ fruits from interspecific crosses between $P$. cerasifera and $P$. armeniaca where seeds of different sizes are present because of embryo abortion. Embryo development in these crosses was arrested at an early stage as a result of incompatibility barriers (Arbeloa et al., 2006). The three 'Myrobalan' clones ('Myrobalan 1' to 'Myrobalan 3') were pollinated for these interspecific crosses.

Culture conditions: culture media, presence of cotyledons, and stratification temperature. The immature open-pollinated fruits were harvested, seeds were excised, and the embryos were dissected in aseptic conditions. Embryo length was recorded at the time of culture. To study the possible effect of cotyledons on germination, three explant types were tested: embryos with full cotyledons, embryos with cotyledons cut in half, or isolated embryonic axis without cotyledons. Two types of culture media were used: 1) the Chée and Pool (1987) medium (C2d) and 2) a Murashige and Skoog (1962) medium (MS) with increased thiamine concentration to $1.19 \mu \mathrm{M}$. Both media did not contain growth regulators, but did contain $87.6 \mathrm{~mm}$ sucrose gelled with $0.7 \%$ DifcoBacto agar and they were dispensed $(10 \mathrm{~mL}$ each) into test tubes (25 $\mathrm{mm}$ diameter) covered with polypropylene caps. Sixteen seeds of each type were cultured.

Seeds were stratified in vitro at a low temperature until the roots emerged ( 2 to 3 months) as seen by regular monitoring. Two stratification temperatures, 0 and $4{ }^{\circ} \mathrm{C}$, were tested during the stratification period in the dark. The embryos were then placed in a culture chamber at $24{ }^{\circ} \mathrm{C}$ with a photoperiod of $16 \mathrm{~h}$ and $35 \mu \mathrm{mol} \cdot \mathrm{m}^{-2} \cdot \mathrm{s}^{-1}$ of light intensity provided by cool-white fluorescent tubes. The germination was scored once the root and a small shoot (1 to $2 \mathrm{~mm}$ ) emerged.

Effect of the embryo size. The $\mathrm{F}_{1}$ fruits from the three maternal genotypes ('Myrobalan 1' to 'Myrobalan 3') (Arbeloa et al., 2006) were harvested 12 weeks after pollination and the embryos excised in aseptic conditions. The embryo length was measured before sowing, and the embryos were grouped into five classes (Table 1). A total of 241 embryos from the three 'Myrobalan' trees were tested. The embryo size ranged from 0.5 to $2 \mathrm{~mm}$ to 8.5 to $10 \mathrm{~mm}$ with the full size of the embryo at $10 \mathrm{~mm}$.

Germination was assessed by observation of the embryo development as described in the previous experiments.

Data analysis. The embryo germination data were compared with the proportion test ("prop. test") of the $\mathrm{R}$ statistical package 
Table 1. Number of embryos cultured for each length class and genotype.

\begin{tabular}{lccrr}
\hline Embryo length classes & Myrobalan 1-F & Myrobalan 2-F & Myrobalan 3-F $_{1}$ & Total \\
\hline $1(0.5-2 \mathrm{~mm})$ & 3 & 23 & 17 & 43 \\
$2(2.5-4 \mathrm{~mm})$ & 10 & 10 & 19 & 39 \\
$3(4.5-6 \mathrm{~mm})$ & 15 & 13 & 37 & 65 \\
$4(6.5-8 \mathrm{~mm})$ & 77 & 27 & 94 & 198 \\
$5(8.5-10 \mathrm{~mm})$ & 47 & 14 & 180 & 241 \\
\hline
\end{tabular}

(R Development Core Team, 2008). This test calculates the $\chi^{2} \mathrm{~s}$ and their corresponding significance ( $P$ values). Germination of the embryos of different sizes was analyzed by using the previously mentioned prop. test to look for independence between both germination and size and germination and genotype. In addition, the effect of embryo size on germination was studied with the same statistical package by using logistic regression analysis of the germination probabilities transformed with the logit link function to fit generalized linear models with binomial errors and to obtain deviance tables that are analogous to analysis of variance tables (Dalgaard, 2002).

\section{Results}

Culture conditions: culture media, presence of cotyledons, and stratification temperature. Germination took place once the embryos were placed in the culture chamber at $24{ }^{\circ} \mathrm{C}$ after stratification. Germination commonly started with root emergence (Fig. 1A) followed by shoot emergence (Fig. 1B).

Neither the culture media nor the presence or absence of cotyledons showed statistically significant differences in the embryo germination rate (Table 2). Germination in both media was very close and ranged from $85 \%$ to $89 \%$. Likewise, germination was also very similar for the three explant types and ranged from $84 \%$ to $90 \%$ (Table 2 ).

Two different stratification temperatures, 0 and $4{ }^{\circ} \mathrm{C}$, were tested before germination in a culture chamber at $24^{\circ} \mathrm{C}$. Germination was highly influenced by the stratification temperature. The temperature had a noticeable effect because only $26 \%$ of the seeds germinated at $0{ }^{\circ} \mathrm{C}$, but germination increased up to $82 \%$ at $4{ }^{\circ} \mathrm{C}$. Differences in germination rate at 0 or $4{ }^{\circ} \mathrm{C}$ are statistically significant at the $P \leq 0.05$ level following a $\chi^{2}$ test. No rosettetype plants were present among the germinated plants after stratification at 0 or $4{ }^{\circ} \mathrm{C}$.

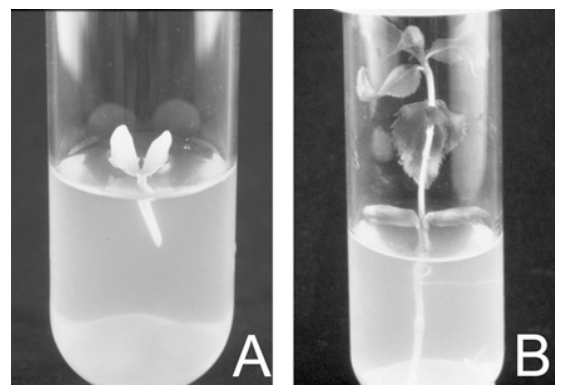

Fig. 1. (A) Radicle emergence in a 'Myrobalan' embryo with full cotyledons after 2 months of stratification at $4{ }^{\circ} \mathrm{C}$. (B) Germinated embryo $14 \mathrm{~d}$ after growth in a culture chamber at $24^{\circ} \mathrm{C}$ showing both the developed shoot and root.
Effect of embryo size. From the results of the previous experiments, the following experimental conditions were chosen to study the effect of embryo size on germination rate. Embryos with full cotyledons were cultured in $\mathrm{C} 2 \mathrm{~d}$ medium and were stratified at $4{ }^{\circ} \mathrm{C}$. Because cross-pollinated fruits $\left(\mathrm{F}_{1}\right)$ were used, the seed size varied from 0.5 to $10 \mathrm{~mm}$ in the three 'Myrobalan' genotypes, which represents $5 \%$ to $100 \%$ of final seed size. The embryos were more abundant in larger Classes 4 and 5 (6.5 to $10 \mathrm{~mm}$ in length), although all categories were represented in the three genotypes (Table 1).

We achieved an overall germination rate with size, and the different genotypes had a similar trend (Fig. 2A). The embryos sized between 6.5 and $10 \mathrm{~mm}$ in length reached a germination rate of $90 \%$ of the seeds, whereas the embryos sized between 4.5 and $6 \mathrm{~mm}$ (Class 3) reached a germination rate of $72 \%$ (Fig. 2B). In addition, although an adequate germination rate of $50 \%$ was already achieved at a size of 2.5 to $4 \mathrm{~mm}$ in length (Fig. 2B), effective germination resulted even in aborted seeds from 0.5 to $2 \mathrm{~mm}$ in length (Class 1), because a percentage of $23 \%$ to $33 \%$ of the embryos grew into plants (Fig. 2A).

Within each $F_{1}$ genotype, there was significant regression between germination and the rank of the embryo size after a logistic regression analysis of the transformed germination probabilities, indicating a direct effect of the embryo size on germination; thus, logistic regression models explained between $72 \%$ and $88 \%$ of the deviance found depending on the genotype, being highest when data were pooled (94\%) (Fig. 2B). There were no significant differences in the germination rate between the genotypes for each embryo size, except in size Class 4 (6.5 to $8 \mathrm{~mm})$ in which 'Myrobalan 3 ' $-\mathrm{F}_{1}$ displayed a significantly higher rate than 'Myrobalan 1'- $F_{1}$ and 'Myrobalan 2'- $F_{1}$. The genotypes 1 and 2 did not show any significant differences between them (Fig. 2A).

\section{Discussion}

We achieved an adequate and elevated in vitro germination rate of 'Myrobalan' embryos of $81 \%$ of the seeds. Germination increased Skoog (MS)]

NS $=$ Nonsignificant difference. by using a set of culture conditions defined in our protocol. The proposed protocol for in vitro 'Myrobalan' embryo culturing includes the use of whole embryos cultured on Chée and Pool medium (C2d), their stratification at $4{ }^{\circ} \mathrm{C}$, and posterior growth in a chamber at $24{ }^{\circ} \mathrm{C}$. Additionally, in this work, we have confirmed a strong influence of embryo size on the germination rate of 'Myrobalan'.

Two different culture media were tested here and showed no differences in embryo germination for 'Myrobalan'. Although the Chée and Pool (1987) culture medium has been recommended for the plum embryos (Emershad and Ramming, 1994), in this work, we found that both the Chée and Pool medium and the MS medium work well for 'Myrobalan'. Growth regulators were not used because they are not a requirement when the embryo has already reached a particular size or an autotrophic stage (Raghavan, 2003). In our case, germination at a lower rate was reached even in small-sized embryos $(0.5$ to $2 \mathrm{~mm}$ in length) without growth regulators.

Our results show that the absence or presence of full or half cotyledons did not improve germination. All three types of explants tested did not show differences in their germination rate. Cotyledons have the ability to inhibit growth in peach, forming a dwarf plant, but this can be overcome by cotyledon removal or chilling treatments (Taiz and Zeiger, 2002). The presence of cotyledons in 'Myrobalan' seeds did not reduce the germination rate, as has been seen in other recalcitrant seeds (Sánchez-Romero et al., 2007) nor did it produce dwarf plants; therefore, the use of intact embryos with cotyledons will facilitate seed manipulations.

To overcome dormancy, the stratification temperature played a critical role in 'Myrobalan' seeds, resulting in a higher number of germinated plants at $4{ }^{\circ} \mathrm{C}$ than at $0{ }^{\circ} \mathrm{C}$, although the effect of low temperature has been shown to be genotype-dependent (Daorden et al., 2002, 2004). The mechanism of dormancy is present in the seeds of Prunus species (García-Gusano et al., 2004; Hartmann et al., 1990). The dormancy period was required, even for germination of immature embryos of Prunus domestica (Kukharchyk and Kastrickaya, 2006) and to avoid rosette-type plants (Burgos and Ledbetter, 1993). In several species of Prunus, different temperatures have been used for seed stratification, ranging from $0.5{ }^{\circ} \mathrm{C}$ (Emershad and Ramming, 1994; Ramming, 1990) to $5^{\circ} \mathrm{C}$ (Anderson et al., 2002; Ledbetter et al., 1998). However, the use of different temperatures has not been compared in one seed type. In this work, we have shown an

Table 2. Germination percentage of 'Myrobalan' embryos of three different types (full embryos, half cotyledon embryos, and embryonic axis) in two different culture media [C2d and Murashige and

\begin{tabular}{lccc}
\hline Explant/culture medium & C2d & MS & Avg across media \\
\hline Full embryos & 93.7 & 81.2 & $87.5 \mathrm{~ns}$ \\
Half cotyledon embryos & 93.7 & 75 & $84.3 \mathrm{~ns}$ \\
Embryonic axis & 81.2 & 100 & $90.6 \mathrm{~ns}$ \\
Average across explants & $89.6 \mathrm{~ns}$ & $85.4 \mathrm{~ns}$ & \\
\hline
\end{tabular}


A

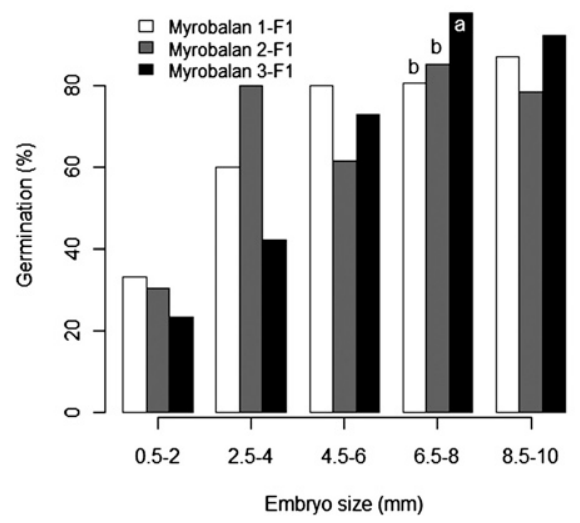

B - Myrobalan-F1 pooled data

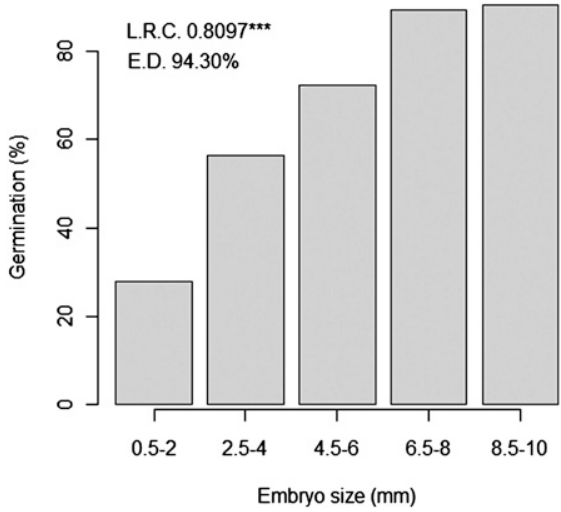

Fig. 2. (A) Germination rate versus embryo size in the F1 of the three 'Myrobalan' clones. Different letters show significant differences in germination at the $P \leq 0.05$ level. (B) Germination rate versus embryo size in the F1 (pooled data). The logistic regression coefficient (LRC) that is analogous to the "slope" in conventional linear regression analysis and the explained deviance (ED) by the model expressed as the percentage of total deviance found in the logistic regression analysis are included $(* * *$ significant at $P \leq 0.001)$.

indisputable effect of temperature on germination rate. The stratification temperature became critical in vitro, and this was also the case with conventional methods (Hartmann et al., 1990; Herrero, 1978).

The germination rate was strongly affected by embryo size. A main factor limiting the successful embryo cultures was the size of the embryo at the time of transfer onto the nutrient medium (Bridgen, 1994; Moore and Janick, 1983). The embryo size depends on the embryo developmental stage (Burgos and Ledbetter, 1993), and many efforts have been devoted in Prunus to find the minimum size at which germination will be successful (Bassi and Infante, 1994; Chaparro and Sherman, 1994; Liu et al., 2007; Sinclair and Byrne, 2003; Stanys, 1998). There is a critical size under which direct embryo germination is not possible, and thus the entire ovule culture should be given time to allow the small embryos to reach the minimum size needed for germination (Hartmann et al., 1990; Sharma et al., 1996), although this size differs among species and conditions. Although these results may seem variable, the result is clear when the embryo size is expressed as a percentage of the final seed size. In our case, an embryo size of $50 \%$ of the final seed size ( $5 \mathrm{~mm}$ in length) had high germination rates (73\%). Below this size $(30 \%$ of the final seed size) had a $50 \%$ rate of germination, and at even smaller sizes ( $2 \mathrm{~mm}$ or less), a $30 \%$ germination rate was achieved, thus allowing for germination of a relatively high percentage of aborted seeds to occur. In other Prunus species, a similar decrease was seen in correlation between germination and seed size. In Prunus avium hybrids, when embryo size was one-third of the seed size, the germination rate was only $40 \%$ (Kukharchyk and Kastrickaya, 2006). Similarly, in Prunus persica hybrids, a critical size of $50 \%$ of seed size was stated to be required for germination (Liu et al., 2007). The seed development model is highly conserved, and these proportions set a baseline for embryo rescue in other Prunus species.
Our results provide an in vitro method for the routine embryo culturing of 'Myrobalan' with a critical embryo size between 4.5 and $6 \mathrm{~mm}$ in length or $45 \%$ to $60 \%$ of the full seed size to achieve high seedling recovery with easy and direct embryo germination. Moreover, this protocol successfully rescues small embryos and will contribute to improve genotype recovery after distant cross-pollinations in fruit breeding programs.

\section{Literature Cited}

Anderson, N., D.H. Byrne, J. Sinclair, and A.M. Burrell. 2002. Cooler temperature during germination improves the survival of embryo cultured peach seed. HortScience 37:402-403.

Arbeloa, A., M.E. Daorden, E. García, A. Wünsch, J.I. Hormaza, and J.A. Marín. 2006. Significant effect of accidental pollinations on the progeny of low setting Prunus interspecific crosses. Euphytica 147:389-394.

Bassi, D. and R. Infante. 1994. Esperienze di embriocoltura nel miglioramento genetico di pesco e ciliegio. Rev di Fruttic. 7-8:65-70.

Bridgen, M.P. 1994. A review of plant embryo culture. HortScience 29:1243-1246.

Burgos, L. and C.A. Ledbetter. 1993. Improved efficiency in apricot breeding: Effects of embryo development and nutrient media on in vitro germination and seedling establishment. Plant Cell Tiss. and Org. Cult. 35:217-222.

Chaparro, J.X. and W.B. Sherman. 1994. Culture date and germination procedure affects success of nectarine ovule and embryo culture. Fruit Var. J. 48:173-175.

Chée, R. and R.M. Pool. 1987. Improved inorganic media constituents for in vitro shoot multiplication of Vitis. Sci. Hort. 32:85-95.

Dalgaard, P. 2002. Introductory statistics with $\mathrm{R}$. Springer, New York, NY.

Daorden, M.E., J.A. Marín, and A. Arbeloa. 2002. Germinación in vitro de embriones inmaduros a distintas temperaturas de estratificación. Itea 98V:71-80.

Daorden, M.E., J.A. Marín, and A. Arbeloa. 2004. Stratification temperature affects in vitro germination of immature Prunus embryos. Acta Hort. 658:135-140.

Emershad, R.L. and D.W. Ramming. 1994. Effects of media on embryo enlargement, germination and plant development in early-ripening genotypes of Prunus grown in vitro. Plant Cell Tiss. and Org. Cult. 37:55-59.

García-Gusano, M., P. Martínez-Gómez, and F. Dicenta. 2004. Breaking seed dormancy in almond [Prunus dulcis (Mill.) D.A.Webb]. Sci. Hort. 99:363-370.

Hartmann, H.T., D.E. Kester, and F. Davies. 1990. Plant propagation. Principles and practices. 5th Ed. Prentice-Hall, Englewood Cliffs, NJ.

Herrero, J. 1978. Estratificado de huesos de ciruelo Mirobolán (Prunus cerasifera Ehrh.). An. Aula Dei 14:173-180.

Kukharchyk, N. and M. Kastrickaya. 2006. Embryo rescue techniques in Prunus L. breeding. J Fruit Ornam. Plant Res. 14:(suppl 1):129-135.

Ledbetter, C.A., D.E. Palmquist, and S.J. Peterson. 1998. Germination and net in vitro growth of peach, almond and peach-almond hybrid embryos in response to mannitol inclusion in the nutrient medium. Euphytica 103:243-250.

Liu, W., X.S. Chen, G.J. Liu, Q. Liang, T.M. He, and J.R. Feng. 2007. Interspecific hybridization of Prunus persica with $P$. armeniaca and $P$. salicina using embryo rescue. Plant Cell Tiss. and Org. Cult. 88:289-299.

Moore, J.N. and J. Janick. 1983. Methods in fruit breeding. Purdue University Press, West Lafayette, IN.

Murashige, T. and F. Skoog. 1962. A revised medium for rapid growth and bioassays with tobacco tissue cultures. Physiol. Plant. 15:473-497.

Okie, W.R. and J.H. Weinberger. 1996. Plums, p. 559-607. In: Janick, J. and J.N. Moore (eds.). Fruit breeding. Vol. I. Tree and tropical fruits. Wiley, New York, NY.

Pinto, A.C.Q., S.M.D. Rogers, and D.H. Byrne. 1994. Growth of immature peach embryos in response to media, ovule support method, and ovule perforation. HortScience 29:1081-1083.

R Development Core Team. 2008. R: A language and environment for statistical computing. $\mathrm{R}$ Foundation for Statistical Computing, Vienna, Austria. 1 June 2009. <http://www.R-project.org>.

Raghavan, V. 2003. One hundred years of zygotic embryos culture investigations. In Vitro Cell. Plant. Dev. Biol. 39:437-442.

Ramming, D.W. 1985. In ovulo embryo culture of early-ripening Prunus. HortScience 20:419-420.

Ramming, D.W. 1990. The use of embryo culture in fruit breeding. HortScience 25:393-398.

Ramming, D.W., R.L. Emershad, and C. Foster. 2003. In vitro factors during ovule culture affect development and conversion of immature peach and nectarine embryos. HortScience 38:424-428

Sánchez-Romero, C., R. Peraìn-Quesada, B. Maìrquez-Martiìn, A. Barceló-Muñoz, and F. Pliego-Alfaro. 2007. In vitro rescue of immature avocado (Persea americana mill.) embryos. Sci. Hort. 111:365-370.

Sharma, D.R., R. Kaur, and K. Kumar. 1996. Embryo rescue in plants-A review. Euphytica 89:325-337.

Sinclair, J.W. and D.H. Byrne. 2003. Improvement of peach embryo culture through manipulation of carbohydrate source and $\mathrm{pH}$. HortScience 38:582-585.

Stanys, V. 1998. In vitro techniques to increase the output of cherry seedlings from early-ripening parents. Acta Hort. 468:203-208.

Taiz, L. and E. Zeiger. 2002. Plant physiology. 3rd Ed. Sinauer, Sunderland, MA.

Tukey, H.B. 1933. Artificial culture of sweet cherry embryos. J. Hered. 24:7-12.

Wertheim, S.J. 1998. Rootstock guide. Apple, pear, cherry, European plum. Fruit Research Station, Wilhelminadorp, The Netherlands. 